Original research article

\title{
Finite element analysis of the tibial component alignment in a transverse plane in total knee arthroplasty
}

\author{
Roman Popescu ${ }^{1 *}$, Stefan Cristea ${ }^{1,2}$, Valentin Oleksik ${ }^{3}$, Adrian Marius Pascu ${ }^{3}$, \\ Emil George Haritinian ${ }^{1,4}$ \\ ${ }^{1}$ Carol Davila University of Medicine and Pharmacy, Bucharest, Romania \\ ${ }^{2}$ Saint Pantelimon Emergency Hospital, Department of Orthopaedics and Traumatology, Bucharest, Romania \\ ${ }^{3}$ University of Sibiu, Faculty of Engineering, Department of Industrial Machinery and Equipments, Sibiu, Romania \\ ${ }^{4}$ Clinical Hospital of Orthopaedics and Traumatology and Osteoarticular TB "Foișor", Bucharest, Romania
}

\section{Abstract}

The research aims to analyze the tibial component rotation using the finite element method by resecting the tibia in a transverse plane at an angle between $1.5^{\circ}$ (external rotation) and $-1.5^{\circ}$ (internal rotation). We used a three-dimensional scanner to obtain the tibia's geometrical model of a cadaveric specimen. We then exported the surfaces of the tibial geometrical model through the ComputerAided Three-dimensional Interactive Application (CATIA), which is a Computer-Aided Design (CAD) program. The CAD program threedimensionally shaped the tibial component, polyethylene, and cement. Our analysis determined that the maximum equivalent stress is obtained in the case of proximal tibial resection at $-1.5^{\circ}$ angle in a transverse plane (internal rotation) with a value of $12.75 \mathrm{MPa}$, which is also obtained for the polyethylene (7.693 MPa) and cement (6.6 MPa). The results have shown that detrimental effects begin to occur at $-1.5^{\circ}$. We propose the use of this finite element method to simulate the positioning of the tibial component at different tibial resection angles to appreciate the optimal rotation.
\end{abstract}

Keywords: Finite element analysis; Rotational alignment; Tibial component; Total knee arthroplasty

Highlights:

- Finite element analysis is an important tool for simulating different angles of tibial resection.

- Tibial component malrotation begins to have an adverse effect at more than $-1.5^{\circ}$ in a transverse plane (internal rotation).

- Preoperative planning based on finite element analysis can improve the outcome of total knee arthroplasty.

\section{Introduction}

Total knee arthroplasty (TKA) is the most successful surgical technique used for the severe stage of knee osteoarthritis, with favourable long-term outcomes and significant improvement of the patient's quality of life. However, compared to total hip arthroplasty (7\% rate of unsatisfied patients that underwent total hip arthroplasty - Okafor and Chen, 2019) the rate of unsatisfied patients following TKA is higher (between $4.8 \%$ and 20.5\%) (Maier et al., 2019).

Many complications such as anterior knee pain, patellofemoral instability, joint stiffness, and polyethylene wear, result from the prosthetic components' malrotation, especially the tibial component (Rhee et al., 2018).

Tibial component malrotation is still an important issue, despite the multitude of anatomical landmarks used for positioning, as well as pre-, intra-, and post-operative imaging evaluation of the prosthetic components. Positioning the tibi- al component is as complex as positioning the femoral component because the tibia's geometry is highly variable. Lee et al. (2017) highlight that combined malrotation of the tibial and femoral component may determine anterior knee pain, and Aglietti et al. (2008) sustain that more negative consequences are determined by the combined malrotation of both prosthetic components such as flexion instability and stiffness, and abnormal gait patterns.

The anatomical landmarks of the rotation of the femoral component are: the transepicondylar axis (the axis between the lateral and the medial epicondyle - the lateral epicondyle is more easily identified during surgery after the apex of bony proeminence), the posterior condyle line (tangent line to the most posterior part of the femoral condyles), and the Whiteside line (connection of the center of the intercondylar notch and the lowest point of the trochlear groove anteriorly) (Castelli et al., 2016; Showronek et al., 2021). Compared with the tibial component, the femoral component has the advantage of having a "gold standard" landmark - which is the trans-

\footnotetext{
* Corresponding author: Roman Popescu, 'Carol Davila' University of Medicine and Pharmacy, Rectorate - Dionisie Lupu Street, no. 37, District 1, 020021, Bucharest, Romania; e-mail: roman.popescu@drd.umfcd.ro http://doi.org/10.32725/jab.2021.020

Submitted: 2021-05-17 • Accepted: 2021-09-20 • Prepublished online: 2021-09-20

J Appl Biomed 19/4: 234-239 • EISSN 1214-0287 • ISSN 1214-021X

(c) 2021 The Authors. Published by University of South Bohemia in České Budějovice, Faculty of Health and Social Sciences.

This is an open access article under the CC BY-NC-ND license.
} 
epicondylar axis (Asano et al., 2005; Berger et al., 1993; Jang et al., 2019; Victor, 2009). Despite the "gold standard" landmark, the rotational alignment of the femoral component is also as much of a challenge as the rotation of the tibial component; still, in our study we preferred to choose the tibial component, largely because of the absence of a "gold standard" landmark due to the tibia's geometry.

In the current literature, tibial component rotation is a frequently approached topic. This is mainly because an anatomical landmark "gold standard" has not been found yet, and the malrotation of the tibial component is the main factor for the patient's dissatisfaction after TKA (Maier et al., 2019). Several anatomical landmarks have been proposed as reproducible and reliable for guiding the tibial component, including Akagi's line and the anterior tibial cortex (Hanada et al., 2019; Kim et al., 2017; Saffarini et al, 2019).

A new technique "Kingpin" uses the Whiteside line (also named transverse axis of the femoral component, which extends from the trochlear groove to the lateral edge of the posterior cruciate ligament; Babazadeh et al., 2009) and extends it distally for the positioning of the tibial component. This technique is considered an auxiliary method for the surgeon to achieve an optimal tibial component rotation (Arnaout and Holt, 2020). Positioning the tibial component using the extra-articular landmarks is not recommended due to the frequent errors in rotation that may occur (Ma et al., 2019).

The purpose of our experimental analysis is to simulate, using the finite element method, the positioning of the tibial component at certain angles. We will do this by cutting the tibia in transverse plane at an angle between $1.5^{\circ}$ (representing external rotation from neutral positioning) and $-1.5^{\circ}$ (representing internal rotation from neutral positioning) to observe the tibial component's behaviour (particularly the rate of wear of the polyethylene). Through this method we are also able to determine the negative impact of malrotation on the outcome in TKA.

\section{Materials and methods}

We scanned the tibia's geometrical model of a cadaveric specimen (the tibia had no previous bone pathologies or deformities, and the mechanical properties of the tibia are described in Table 1), using a three-dimensional scanner, after we obtained cross sectional images of the tibia through computer tomography. To export the surfaces of the tibial geometrical model in Computer-Aided Design (CAD) program, we used the Computer-Aided Three-dimensional Interactive Application (CATIA) after the scan had been performed. After correcting geometrical inaccuracies, we used the Abaqus software for the finite element analysis. We also used the CAD program to three-dimensionally shape the tibial component, polyethylene and cement. Meshing in finite elements through the CAD program is necessary due to geometry. Afterwards the type of element, the material, and geometrical data used were attached (Danczyk and Suresh, 2012; Fries and Belytschko, 2010; Mac Donald, 2007). We took into consideration the longitudinal modulus of elasticity (measured in gigapascal - GPa) and Poisson Ratio as the most important material data.

Meshing is necessary to reduce the tibia's geometric complexity and the time for analysis. For our study, we used the "surface on surface" contact for interface condition, after importing and meshing all the component's elements. According to specialty literature, there are three phases of analysis through finite element - pre-processing, solving and post-processing. The pre-processing phase implies meshing, definition of materials and applying boundary conditions. It is important to mention the boundary conditions because they define the

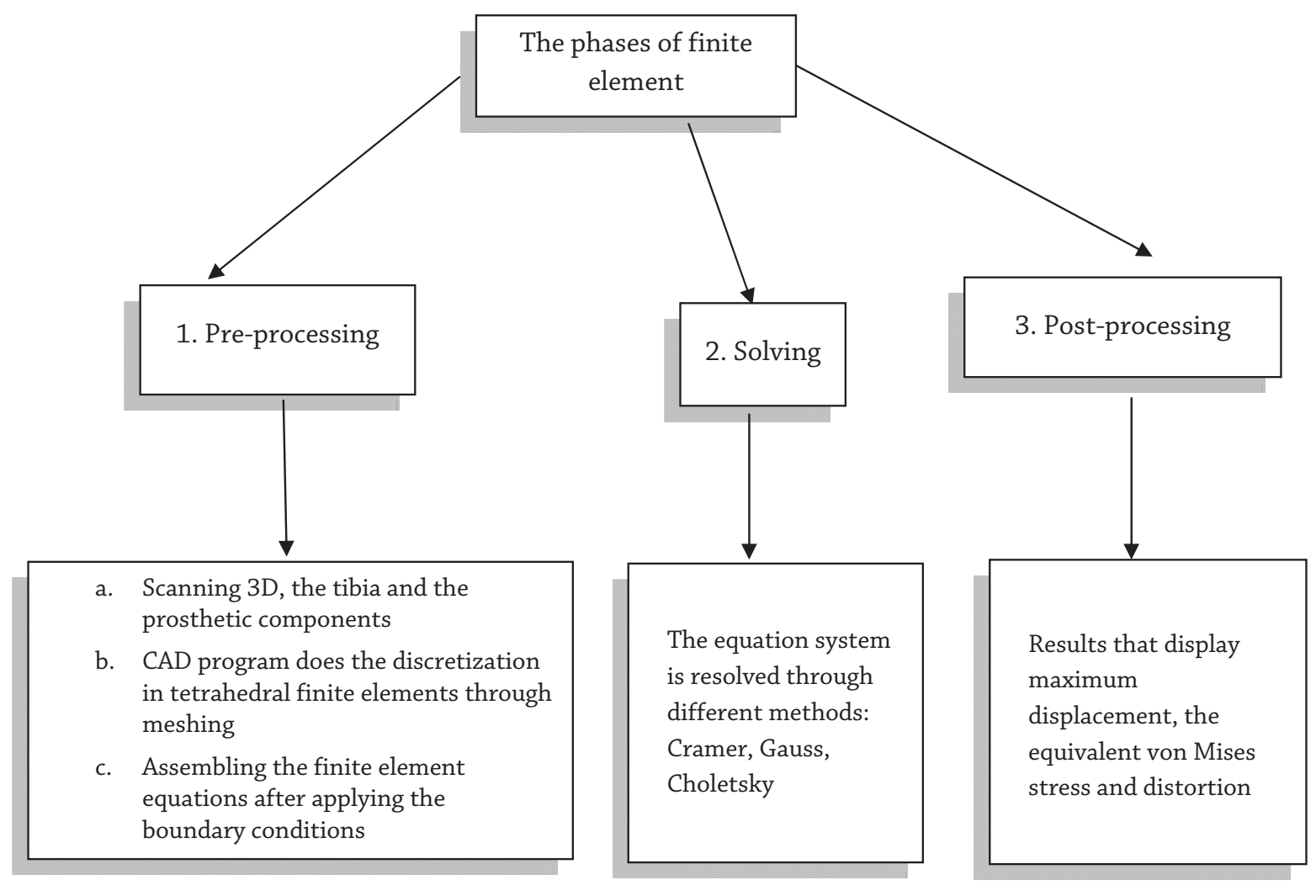


Table 1. Material data for tibia and prosthetic components in TKA

\begin{tabular}{lcc}
\hline Component & Modulus (GPa) & Poisson ratio \\
\hline Tibia & 6 & 0.3 \\
Polyethylene & 10.9 & 0.46 \\
Tibial component & 113.8 & 0.265 \\
Cement & 14 & 0.1 \\
\hline Legend: GPa - gigapascal. & &
\end{tabular}

external forces exerted on the tibia and the prosthetic components. So, in our study we used a load of $1000 \mathrm{~N}$ in order to see how it affects the prosthetic components at different tibial cuts in transverse plane $\left(-1.5^{\circ}\right.$ and $\left.1.5^{\circ}\right)$, this being sufficient to perform a successful calculation. After running all the phases, the last one allows us to calculate the maximum displacement of components (provides information about the geometric deflections of the tibia and the prosthetic components), the equivalent von Mises stress (allows to determine the mechanical durability of the bone and prosthetic components) and distortion. In order to ensure the accuracy of the calculations (the absence of standard error), we used the application of calculation verification - which estimates the numerical error associated with the discretization.

\section{Results}

In the transverse plane, the proximal tibial cut was made at a $1.5^{\circ}$ (external rotation) and at $-1.5^{\circ}$ (internal rotation) determining the nodal displacement, equivalent stress and distortion at these values for the tibia. The equivalent von Misses stress and the main maximum distortion were calculated for the polyethylene, tibial component and cement (Tables 3-5).

The equivalent von Mises stress represents the maximum limit of the bone hardness, after which the bone breaks. The equivalent von Misses distortion represents the maximum capacity of a material to deform, and the nodal displacements show how the stress is spreading through the bone in the three directions of the coordinate axes (Table 2, Figs 1-2).

Table 2. Results obtained for the tibia

\begin{tabular}{lccc}
\hline Analysis & $\begin{array}{c}\text { Equivalent } \\
\text { stress } \\
{[\mathrm{MPa}]}\end{array}$ & $\begin{array}{c}\text { Equivalent } \\
\text { distortion } \\
{[\mathrm{mm}]}\end{array}$ & $\begin{array}{c}\text { Nodal } \\
\text { displacement } \\
{[\mathrm{mm}]}\end{array}$ \\
\hline $\begin{array}{l}\text { Proximal tibial cut at } \\
1.5^{\circ}-\text { transverse plane } \\
\text { (external rotation) }\end{array}$ & 5.00 & 0.001 & 0.069 \\
\hline $\begin{array}{l}\text { Proximal tibial cut at } \\
-1.5^{\circ}-\text { transverse plane } \\
\text { (internal rotation) }\end{array}$ & 12.75 & 0.001 & 0.074 \\
\hline
\end{tabular}

Table 3. Results obtained for the tibial component

\begin{tabular}{lcc}
\hline Analysis & $\begin{array}{c}\text { Equivalent stress } \\
{[\mathrm{MPa}]}\end{array}$ & $\begin{array}{c}\text { Equivalent } \\
\text { distortion }[\mathrm{mm}]\end{array}$ \\
\hline $\begin{array}{l}\text { Proximal tibial cut at } 1.5^{\circ}- \\
\text { transverse plane (external } \\
\text { rotation) }\end{array}$ & 10 & 0.00015 \\
\hline $\begin{array}{l}\text { Proximal tibial cut at }-1.5^{\circ} \\
- \text { transverse plane (internal } \\
\text { rotation) }\end{array}$ & 10 & 0.00015 \\
\hline
\end{tabular}

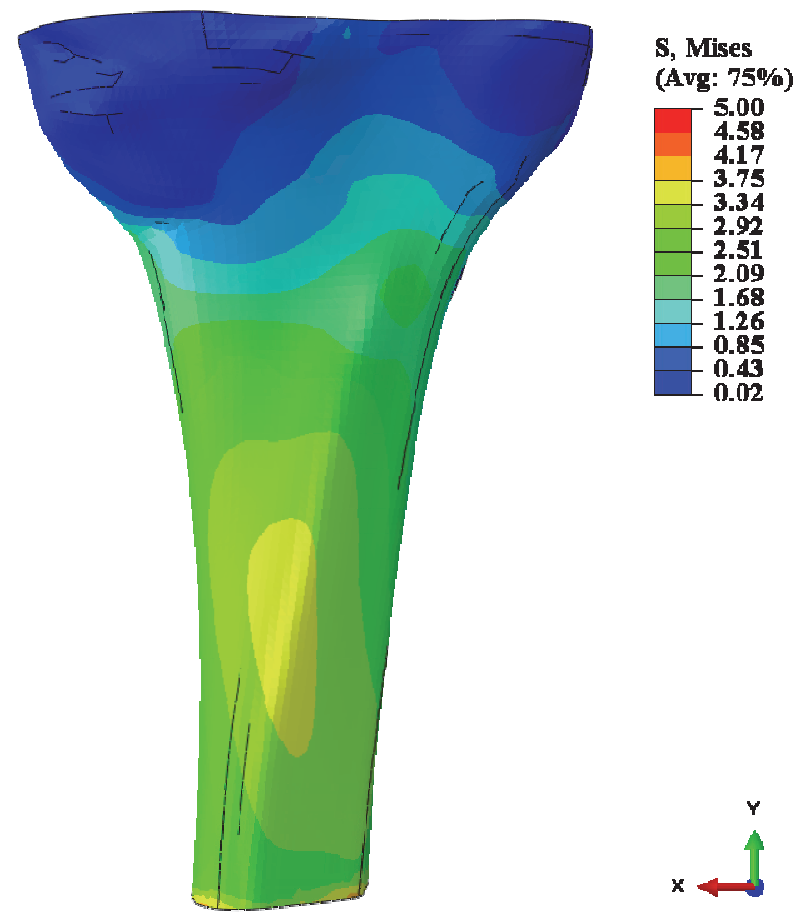

Fig. 1. Variation of the equivalent von Mises stress for tibia in case of proximal resection at $1.5^{\circ}$ angle in transverse plane (external rotation) - frontal view

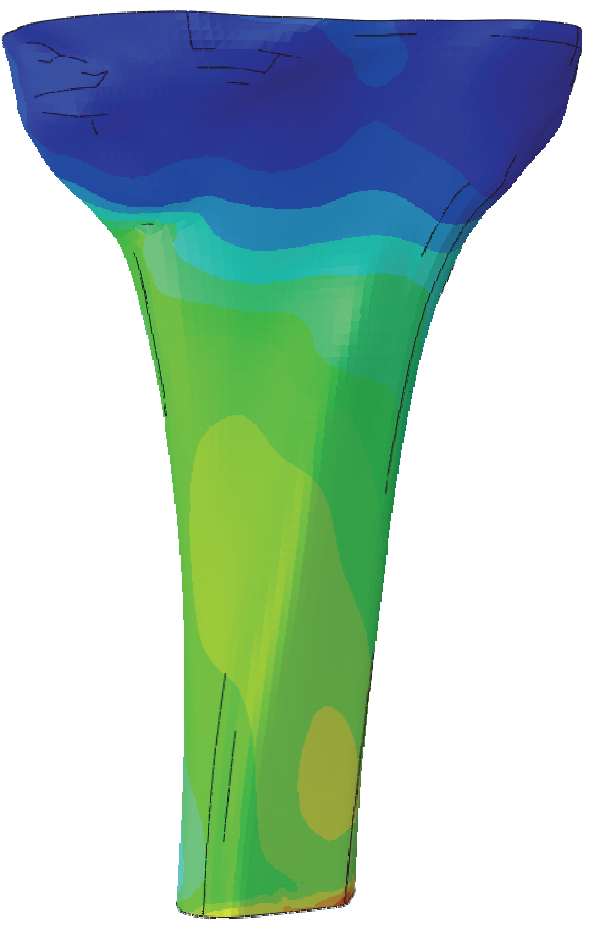

S, Mlses

(Avg: 75\%)

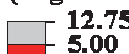

$\mathbf{5 . 0 0}$

$-4.17$

3.34

3.34

$-2.92$

2.50
-2.09

2.09
-1.67

1.67
-1.25

$-0.84$

$-0.42$

Fig. 2. Variation of the equivalent von Mises stress for tibia in case of proximal resection at $-1.5^{\circ}$ angle in transverse plane (internal rotation) - frontal view 
Table 4. Results obtained for the polyethylene

\begin{tabular}{lcc}
\hline Analysis & $\begin{array}{c}\text { Equivalent stress } \\
{[\mathrm{MPa}]}\end{array}$ & $\begin{array}{c}\text { Equivalent } \\
\text { distortion }[\mathrm{mm}]\end{array}$ \\
\hline $\begin{array}{l}\text { Proximal tibial cut at } 1.5^{\circ}- \\
\text { transverse plane (external } \\
\text { rotation) }\end{array}$ & 6.737 & 0.00057 \\
\hline $\begin{array}{l}\text { Proximal tibial cut at }-1.5^{\circ} \\
- \text { transverse plane (internal } \\
\text { rotation) }\end{array}$ & 7.693 & 0.00067 \\
\hline
\end{tabular}

Table 5. Results obtained for the cement

\begin{tabular}{lcc}
\hline Analysis & $\begin{array}{c}\text { Equivalent stress } \\
{[\mathrm{MPa}]}\end{array}$ & $\begin{array}{c}\text { Equivalent } \\
\text { distortion }[\mathrm{mm}]\end{array}$ \\
\hline $\begin{array}{l}\text { Proximal tibial cut at } 1.5^{\circ}- \\
\text { transverse plane (external } \\
\text { rotation) }\end{array}$ & 3.1 & 0.00020 \\
\hline $\begin{array}{l}\text { Proximal tibial cut at }-1.5^{\circ} \\
- \text { transverse plane (internal } \\
\text { rotation) }\end{array}$ & 6.6 & 0.00020 \\
\hline
\end{tabular}

Our analysis determined that the maximum equivalent stress for the tibia, polyethylene and cement is obtained in the case of proximal tibial resection at $-1.5^{\circ}$ angle in transverse plane (internal rotation). Regarding the tibial component, the equivalent stress had the same value for both studied angles in the transverse plane.

\section{Discussion}

The rotation of the tibial component in TKA is still a debatable subject and it is important because malrotation determines joint instability, tibiofemoral and patellofemoral kinematic issues and thus affects the clinical outcome (Seo et al., 2015).

Previous studies have proven the importance of finite element in the orthopaedic field and have guided the surgeons to better position the tibial component in the sagittal and frontal planes. Still, the optimal positioning of the tibial component has not been defined in the rotational plane, thus resulting in higher revision rates (Sahu and Kaviti, 2016; Wernecke et al., 2016).

Dong et al. (2020) used the finite element method to simulate the effect of different angles in the three planes (frontal, sagittal and axial) to determine accurate positioning of the tibial component simultaneously in the three planes. They chose to simulate the external rotation of the tibial component at $3^{\circ}$, $4^{\circ}$ and $5^{\circ}$ in transverse plane. They determined that the best positioning in transverse plane is $4^{\circ}$ external rotation associated with $0^{\circ}$ in frontal plane and $1^{\circ}$ in sagittal plane. Although our study did not simultaneously simulate the angles in all the three planes, our results also determined that the external rotation of the tibial component at $1.5^{\circ}$ is better than internal rotation at $-1.5^{\circ}$.

Yamamura et al. (2020) compared conventional patient-specific instrumentation and a newly designed patient-specific instrumentation and found that the new design improved the tibial component rotation. However, while the positioning in axial plane was improved, the internal malrotation $>3^{\circ}$ still caused complications.

Watanabe et al. (2014) found that anterior knee pain is associated with a $6.2^{\circ}$ internal rotation of the tibial component. And Abdelnasser et al. (2020) explained that the internal malrotation of the tibial component causes a post-operative deficit in lower limb extension. They also found that patellar subluxation was determined by an internal rotation of the tibial component at a value between $3^{\circ}$ and $8^{\circ}$, and the patellar luxation occured at a value starting at $7^{\circ}$.

Ammantullah et al. (2018) suggested that malrotation of the tibial component occurs more frequently in the case of pre-existing deformations or inadequate tibial resection. One study shows that a $10^{\circ}$ flexion contracture and a $15^{\circ}$ varus deformity determine internal malrotation of $2.6^{\circ}$ (Watanabe et al., 2014), suggesting that the supposition of Ammantulah et al. (2018) is accurate.

Babazadeh et al. (2019) found that an internal malrotation of the tibial component of more than $6^{\circ}$ was associated with anterior knee pain. Likewise, they asserted that it is difficult to define the optimal rotation for the tibial component in order to prevent short or long-term post-operative complications.

Referring to anatomical landmarks, Nedopil et al. (2016) included four reference lines (between the most medial and lateral portion of the tibial plateau, between the medial onethird of the tubercle and the center of the posterior cruciate ligament insertion, between the medial border of the tibia and posterior cruciate ligament, between the projection of the anterior cortex and the posterior cruciate ligament) that determined a variation of the tibial component rotation from $-44^{\circ}$ internal rotation to $46^{\circ}$ external rotation, thus suggesting that these lines cannot be used as landmarks. Their study also suggested that a variation from $-11^{\circ}$ internal rotation to $12^{\circ}$ external rotation does not affect pain scores, which does not exclude the possibility that such variations may affect the TKA outcome and long-term tibial component survival.

Osano et al. (2014) concluded that the internal rotation of the tibial component determined an increased stress level on the polyethylene. They also demonstrated an increase of $15 \%$ of the maximum von Mises stress in case of internal rotation, which is consistent with our findings.

The consequences of tibial component internal rotation have been debated and discussed in other papers (Liu et al., 2020; Nam et al., 2020; Planckaert et al., 2018), and even though the literature data imply different resection angles that determine internal rotation of the tibial component, the particularity of our study lies in the fact that our analysis used the finite element method, which allowed us to determine the minimum value threshold that determines micro changes of the tibia, cement and polyethylene without causing symptoms.

The results obtained in our study demonstrate that the proximal tibial cut at $-1.5^{\circ}$ (internal rotation) in a transverse plane compared to $1.5^{\circ}$ (external rotation) loads the tibia, the polyethylene and the cement with greater stress. This suggests that it is better to position the tibial component in external rotation, in order to reduce the risks of loosening and polyethylene wear.

One limitation of our study is the fact that we did not compare the results for the cadaveric tibia with the patients' tibia (that implies a dynamic analysis, which could probably change the boundary conditions). At the same time, the possibility of using different resection angles to obtain results that are comparable with the literature values also implies a dynamic analysis. These limitations also represent future research directions we intend to carry out.

Another limitation of the study is the absence of deformities or other pathologies of the cadaveric tibia. At the same time, the individual variability could not be taken into consideration because the meshed tibia was created based on a single cadaveric specimen. 
Currently, to the best our knowledge, it has not been claimed or demonstrated in literature that variations in the rotation of the tibial component in transverse plane of $\pm 1.5^{\circ}$ are meaningful or relevant. Our analysis argues that even such a small difference in rotation can have a significant impact. In the future, the finite element method may improve clinical results by becoming a useful tool in the preoperative planning of TKA.

\section{Conclusions}

In our experimental study, we demonstrated that the tibial resection at $-1.5^{\circ}$ angle in the transverse plane (internal rotation of the tibial component) represents the minimum threshold at which the tibial component malrotation begins to cause unfavorable consequences.

Using the finite element to adjust the rotation of the tibial component can help obtain an ideal alignment, which is associated with reduced risk of complications and a longer prosthesis survival. Our findings are consistent with the literature data and have led us to recommend the creation of a preoperative planning.

We propose using the finite element method to simulate the positioning of the tibial component at different tibial resection angles, in order to achieve optimal rotation.

\section{Funding}

No funding was received.

\section{Availability of data and materials}

Data and materials are available from the corresponding author on reasonable request.

\section{Ethical aspects and conflict of interests}

The authors have no conflict of interests to declare.

\section{References}

Abdelnasser MK, Adi MM, Elnaggar AA, Tarabichi S (2020). Internal rotation of the tibial component in total knee arthroplasty can lead to extension deficit. Knee Surg Sports Traumatol Arthrosc 28(9): 2948-2952. DOI: 10.1007/s00167-019-05695-w.

Aglietti P, Sensi L, Cuomo P, Ciardullo A (2008). Rotational position of femoral and tibial components in TKA using the femoral transepicondylar axis. Clin Orthop Relat Res 466(11): 2751-2755. DOI: 10.1007/s11999-008-0452-8.

Ammantullah DF, Pallante GD, Ollivier MP, Hooke AW, Abdel MP, Taunton MJ (2018). Experience influences the agreement and reliability of tibial component positioning in total knee arthroplasty. J Arthroplasty 33: 1231-1234. DOI: 10.1016/j. arth.2017.11.012.

Arnaout F, Holt G (2020). The Kingpin Technique: An aid for optimal tibial component rotation during total knee arthroplasty. Int J Orth 7(2): 1245-1247. DOI: 10.17554/j.issn.23115106.2020.07.355.

Asano T, Akagi M, Nakamura T (2005). The functional flexionextension axis of the knee corresponds to the surgical epicondylar axis: in vivo analysis using a biplanar image-matching technique. J Arthroplasty 20(8): 1060-1067. DOI: 10.1016/j. arth.2004.08.005

Babazadeh S, Dowsey MM, Vasimalla MG, Stoney JD, Choong PFM (2019). Knee arthroplasty component malrotation does not affect function or quality of life in the short to medium term. J Arthroplasty 34(7): 1382-1386. DOI: 10.1016/j. arth.2019.02.056.
Babazadeh S, Stoney JD, Lim K, Choong PFM (2009). The relevance of ligament balancing in total knee arthroplasty: how important is it? A systematic review of the literature. Orthop Rev 1(2): e26. DOI: 10.4081/or.2009.e26.

Berger RA, Rubash HE, Seel MJ, Thompson WH, Crossett LS (1993). Determining the rotational alignment of the femoral component in the total knee arthroplasty using the epicondylar axis. Clin Orthop Relat Res 286: 40-47.

Castelli CC, Falvo DA, Iapicca ML, Gotti V (2016). Rotational alignment of the femoral component in total knee arthroplasty. Ann Transl Med 4(1): 4. DOI: 10.3978/j.issn.23055839.2015.12.66.

Danczyk J, Suresh K (2012). Finite element analysis over tangled meshes. Proceedings of the ASME 2012 International Design Engineering Technical Conferences and Computers and Information in Engineering Conference. Volume 2: 32nd Computers and Information in Engineering Conference, Parts A and B. Chicago, Illinois, USA, pp. 89-95. DOI: 10.1115/ DETC2012-70466.

Dong Y, Zhang Z, Dong W, Hu G, Wang B, Mou Z (2020). An optimization method for implantation parameters of individualized TKA tibial prosthesis based on finite element analysis and orthogonal experimental design. BMC Musculoskelet Disord 21: 165. DOI: 10.1186/s12891-020-3189-5.

Fries T-P, Belytschko T (2010). The extended/ generalized finite element method: An overview of the method and its applications. Int J Numer Meth Engng 84(3): 253-304. DOI: 10.1002/ nme.2914

Hanada M, Furuhashi H, Matsuyama Y (2019). Investigation of the control of rotational alignment in the tibial component during total knee arthroplasty. Eur J Orthop Surg Traumatol 29(6): 1313-1317. DOI: 10.1007/s00590-019-02427-1.

Jang ES, Connors-Ehler R, LiArno S, Geller JA, Copper J, Shah RP (2019). Accuracy of reference axes for femoral component rotation in total knee arthroplasty. J Bone Joint Surg Am 101(23): e125. DOI: 10.2106/JBJS.19.00438.

Kim JI, Jang J, Lee KW, Han HS, Lee S, Lee MC (2017). Anterior tibial curved cortex is reliable landmark for tibial rotational alignment in total knee arthroplasty. BMC Musculoskelet Disord 18: 252. DOI: 10.1186/s12891-017-1609-y.

Lee JK, Lee S, Chun SH, Kim KT, Lee MC (2017). Rotational alignment of femoral component with different methods in total knee arthroplasty: a randomized, controlled trial. BMC Musculoskeletal Disorders 18: 217. DOI: 10.1186/s12891-0171574-5.

Liu M-Y, Wang H-B, Liu S-W, Zhang G-P, Liu J-G, Yang C (2020). Three-point Method to Guide the Tibial Resection and Component Placing in Total Knee Arthroplasty. Orthop Surg 12(3): 861-868. DOI: 10.1111/os.12693.

Ma Y, Mizu-Uchi H, Ushio T, Hamai S, Akasaki Y, Murakami K, Nakashima Y (2019). Bony landmarks with tibial cutting surface are useful to avoid rotational mismatch in total knee arthroplasty. Knee Surg Sports Traumatol Arthrosc 27(5): 1570-1579. DOI: 10.1007/s00167-018-5052-x.

Mac Donald BJ (2007). Practical stress analysis with finite elements (Modelling and meshing). 2nd ed. Chapter 6, Glasnevin Publishing, Ireland, pp. 179-210.

Maier MW, Aschauer S, Wolf SI, Dreher T, Merle C, Bitsch RG (2019). Three dimensional gait analysis in patients with symptomatic component malrotation after total knee arthroplasty. Int Orthop 43: 1371-1378. DOI: 10.1007/s00264-018-4118-1.

Nam J-H, Koh Y-G, Kim PS, Kim G, Kwak YH, Kang KT (2020). Evaluation of tibial rotat-ional axis in total knee arthroplasty using magnetic resonance imaging. Sci Rep 10(1): 14068. DOI: 10.1038/s41598-020-70851-z.

Nedopil AJ, Howell SM, Hull ML (2016). Does malrotation of the tibial and femoral components compromise function in kinematically aligned total knee arthroplasty? Orthop Clin North Am 47(1): 41-50. DOI: 10.1016/j.ocl.2015.08.006.

Okafor L, Chen AF (2019). Patient satisfaction and total hip arthroplasty: a review. Arthroplasty 1: 6. DOI: 10.1186/s42836019-0007-3. 
Osano K, Nagamine R, Todo M, Kawasaki M (2014). The effect of malrotation of tibial component of total knee arthroplasty on tibial insert during high flexion using a finite element analysis. Scientific World J 2014: 695028. DOI: 10.1155/2014/695028.

Planckaert C, Larose G, Ranger P, Lacelle M, Fuentes A, Hagemeister N (2018). Total knee arthroplasty with unexplained pain: new insights from kinematics. Arch Orthop Trauma Surg 138(4): 553-561. DOI: 10.1007/s00402-018-2873-5.

Rhee SJ, Cho JY, Jeung SH, Poon KB, Choi YY, Suh JT (2018). Combined rotational alignment change after total knee arthroplasty in different tibial component designs: implications for optimal tibial component rotational alignment. Knee Surg Relat Res 30(1): 74-83. DOI: 10.5792/ksrr.17.048.

Saffarini M, Nover L, Tandogan R, Becker R, Moser LB, Hirschmann M, Indelli PF (2019). The original Akagi line is the most reliable: a systematic review of landmarks for rotational alignment of the tibial component in TKA. Knee Surg Sports Traumatol Arthrosc 27(4): 1018-1027. DOI: 10.1007/s00167018-5131-z.

Sahu NK, Kaviti AK (2016). A review of use FEM techniques in modelling of human knee joint. J Biomim, Biomater Biomech Engineering 28: 14-25. DOI: 10.4028/www.scientific.net/ jbbbe.28.14.

Seo J-G, Moon Y-W, Kim S-M, Park S-H (2015). How to minimize rotational conflict between femoral \& tibial component in total knee arthroplasty - the use of femoro-tibial axial synchronizer (Linker). Yonsei Med J 56(2): 454-459. DOI: 10.3349/ ymj.2015.56.2.454.

Showronek P, Arnold M, Starke C, Bartyzel A, Moser LB, Hirschmann MT, European Knee Associates (EKA) (2021). Intraand postoperative assessment of femoral component rotation in total knee arthroplasty: an EKA knee expert group clinical review. Knee Surg Sports Traumatol Arthrosc 29: 772-782. DOI: 10.1007/ s00167-020-06006-4.

Victor J (2009). Rotational alignment of the distal femur: a literature review. Orthop Traumatol Surg Res 95(5): 365-372. DOI: 10.1016/j.otsr.2009.04.011.

Watanabe S, Sato T, Omori G, Koga Y, Endo N (2014). Change in tibiofemoral rotational alignment during total knee arthroplasty. J Orthop Sci 19(4): 571-578. DOI: 10.1007/s00776-014-0565-8.

Wernecke GC, Harris IA, Seeto BG, Chen DB, MacDessi SJ (2016). Normal femorotibial rotational alignment and implications for total knee arthroplasty: an MRI analysis. HSSJ 12(3): 216-222. DOI: 10.1007/s11420-016-9491-y.

Yamamura K, Minoda Y, Sugama R, Ohta Y, Nakamura S, Ueyama H, Nakamura H (2020). Design improvement in patient-specific instrumentation for total knee arthroplasty improved the accuracy of the tibial prosthetic alignment in the coronal and axial planes. Knee Surg Sports Traumatol Arthrosc 28: 1560-1567. DOI: 10.1007/s00167-019-05571-7. 